\title{
Riñón multicístico
}

DRS, DANIEL MAYNE V.* y COLOMBA NORERO *

El riñón multicístico es la causa más frecuente de tumor abdominal en el recién nacido (1). Constituye además, la forma más frecuente de enfermedad quística congénita del riñón en la lactancia y la que tiene mayor interés ya que su pronóstico es excelente tras la nefrectomía $(3,7,8)$. Cuando pasa idnavertido en el período del recién nacida, puede manifestarse posteriormente por alguna de sus complicaciones o como acompañante de otras patologías del tipo de las displasias o de uropatía obstructiva del Jado opuesto (7).

El pediatra debe plantear con prioridad la hipótesis diagnóstica de riñón multicístico ante todo recién nacido de término o pretérmino al cual se le palpa una masa en flanco e hipocondrio.

Como se trata de una anomalía de tipo estructural congénita, ésta necesariamente guarda relación con alteraciones del desarrollo embriológico del riñón, aunque su patogenia exacta es aún desconocida.

Material y MÉTODo. De 1966 a $1970 \mathrm{en} \mathrm{el}$ Departamento de Pediatría del Hospital San Juan de Dios se han presentado 5 casos de riñón multicístico en los cuales se ha podido hacer un estudio completo. Hemos creído de interés presentar esta casuística analizando las caracteristicas clínicas, de laboratorio, el estudio pielográfico, la cintigrafía renal, el tratamiento, la anatomía patológica y el control alejado de estos niños. Todos estos elementos permiten precisar un cuadro clínico y anatomopatológico bien definido dentro de la patología quística de los riñores.

Resultados. Se pueden analizar en la Tabla No 1. De los cinco casos, cuatro corresponden a

\footnotetext{
* Unidad de Nefrourologia. Departatmento de Pediatria. Hospital San Juan de Dios.
}

recién nacidos y uno a un lactante mayor de un año cinco meses de edad. Tres pertenecían al sexo masculino y dos al femenino. En cuanto a la sintomatología, los cuatro recién nacidos ingresaron por presentar una masa abdominal; el lactante mayor ingresó por una desnutrición acompañada de polidipsia, poliuria y signos de insuficiencia renal. El examen de orina fue normal en los cuatro recién nacidos $\mathrm{y}$ alterado en el lactante que presentaba proteinuria y hematuria sin signos de infección.

La pielografía descendente muestra en todos los casos una exclusión renal en correspondencia con el lado afectado (Fig. № 1). El lactante con insuficiencia renal muestra además al lado opuesto al riñón excluido, un riňón pequeño (Fig. No 2).

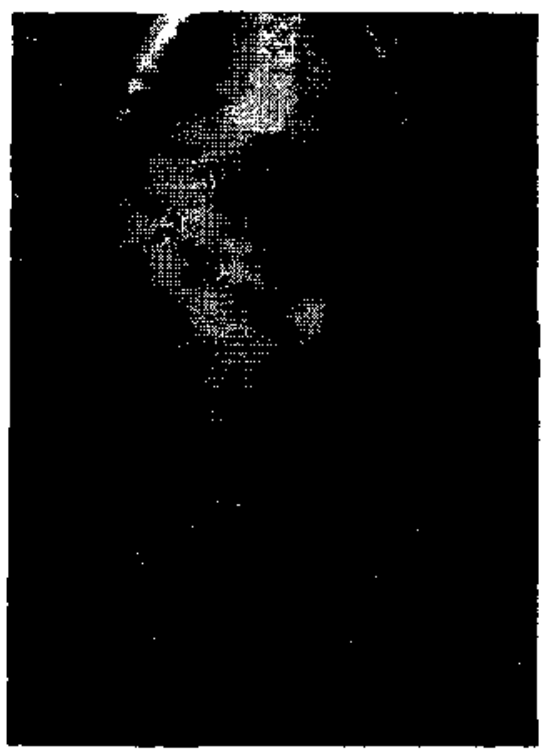

Figura No 1,- Pielografía descendente. Exclusión renal derecha. Rinón Multicístico derecho. 
TABLA No 1

AINON MULTICISTICO: S OBSERVACIONES IINICAS.

\begin{tabular}{|c|c|c|c|c|c|c|c|}
\hline $\begin{array}{l}\text { nombre,edted } \\
\text { soxa }\end{array}$ & motive de consinla & $\begin{array}{l}\text { eximen } \\
\text { orina }\end{array}$ & pretogratis & 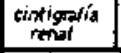 & tratamento & andeforis astorógies & controt atejadn \\
\hline $\begin{array}{l}\text { A.j.p. } \\
\text { R.N.T. } \\
N^{7}\end{array}$ & masa finece derecho & $\begin{array}{l}\text { prot:indicits } \\
\text { uroodt }(-)\end{array}$ & exclusion renal der. & $\begin{array}{l}\text { escaso cont } \\
\text { treste irre- } \\
\text { gutar a der. }\end{array}$ & & 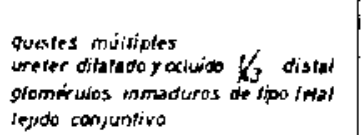 & $\begin{aligned} 7 \text { meses: } P: 7500 \\
f: 63 \mathrm{~cm} \\
\text { ex. cring normad }\end{aligned}$ \\
\hline R.N.r. & mass limco izquierdo & $\left|\begin{array}{l}\text { sed. utr. }(-) \\
\text { unocuth }(-)\end{array}\right|$ & exciusjón rented izọ. & $\begin{array}{l}\text { ausenciz de } \\
\text { contraste a } \\
\text { izq. }\end{array}$ & 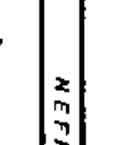 & $\begin{array}{l}\text { ouistes mútliples } \\
\text { ureter reducido cordón fibroso } \\
\text { giomerutos y lubuios en islotes }+0- \\
\text { dilerenciados } \\
\text { lejidos froroso y cartilaginoso }\end{array}$ & $\begin{array}{r}+m: P: 4600 \\
r: 64 \mathrm{~cm} \\
\text { r. orina norma }\end{array}$ \\
\hline R.N.T. & $\begin{array}{l}\text { masa hipocondria } \dot{y} \\
\text { flanco izq. }\end{array}$ & $\left|\begin{array}{l}\text { sed wh }(-) \\
\text { stavil }(-)\end{array}\right|$ & excfustion retal iza. & $\begin{array}{l}\text { ausiensia de } \\
\text { contraste a } \\
\text { irq. }\end{array}$ & 3 & 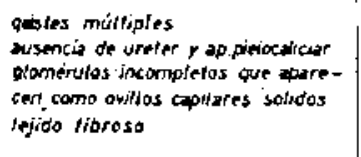 & $\mid \begin{array}{l}\text { It. } 3 \mathrm{~m}: 0: 10.500 \\
1: 74 \mathrm{~cm} \\
\text { o Art. } 80 / 40 \\
\text { ex. Oring normet }\end{array}$ \\
\hline$=\begin{array}{l}\text { pilie: } \\
\text { R.r.t: } \\
9\end{array}$ & (1) 1s iflance der. & $\begin{array}{l}\text { prolindicias } \\
\text { uracutt (-) }\end{array}$ & - kcijión renal der. & - & & $\begin{array}{l}\text { quistes múliples } \\
\text { ureler atrdfito } \\
\text { glomeruios de tipo ferat en islotes } \\
\text { injido tibroso }\end{array}$ & $\begin{array}{l}\text { 32. } 5 \mathrm{~m}: \text { P: } 16 \text { hgs. } \\
\text { ?: } 105 \mathrm{~cm} \\
\text { P.Arl, 100/80 } \\
\text { e. orina normal }\end{array}$ \\
\hline $\begin{array}{l}\text { cets. } \\
10.5 m \\
7 \\
=-1\end{array}$ & $\begin{array}{l}\text { desnutrción: P: } 7550 \\
7: 75 \mathrm{~cm} . \\
\text { potrdipsia. } \\
\text { poluria: } \\
\text { uremia:-lgrm. }\end{array}$ & $\begin{array}{l}\text { prow: indrios } \\
\text { gri: } \\
\text { aberdantes }\end{array}$ & 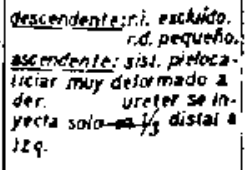 & '; & & $\begin{array}{l}\text { quistes multiples } \\
\text { areiter arrestico } \\
\text { glomérulos ausmies } \\
\text { rejito libroso }\end{array}$ & 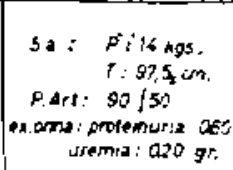 \\
\hline
\end{tabular}

La pielografía ascendente en este caso muestra que el uréter izquierdo se jnyecta sólo en su tercio distal; a derecha muestra un sistema pielocaliciar muy deformado y dilatado (Fig. No 3).

La cintigrafía renal se practicó en los casos uno, dos y tres. En el caso uno muestra un riñón izquierdo de forma, tamaño y contraste normal; a

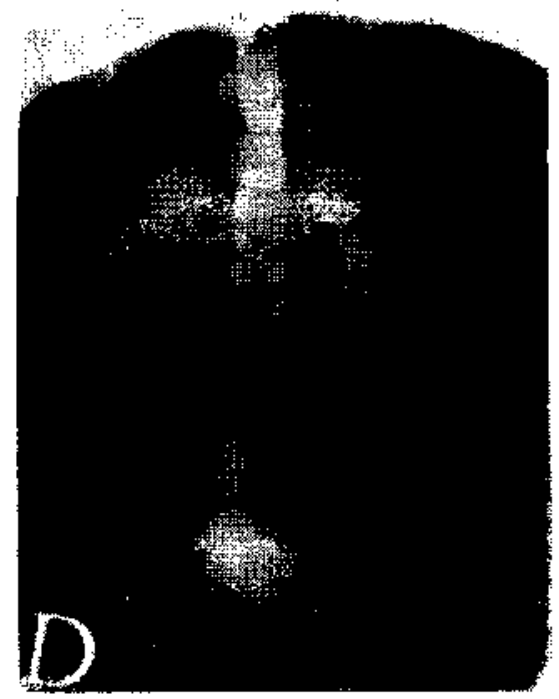

Figura Nọ 2.- Pielografía descendente. Exclusión renal izquierda. Rifón derecho pequefio. Riñón multicístico iz. quierdo y riñon derecho hjpoplásico. derecha existe un escaso contraste irregular que se confunde con la radiactividad hepática (Fig. Nọ 4). Los casos dos y tres muestran ausencia absoluta de contraste en el lado afectado (Fig. № 5 ).

El tratamiento en todos los casos fue la nefrectomía.

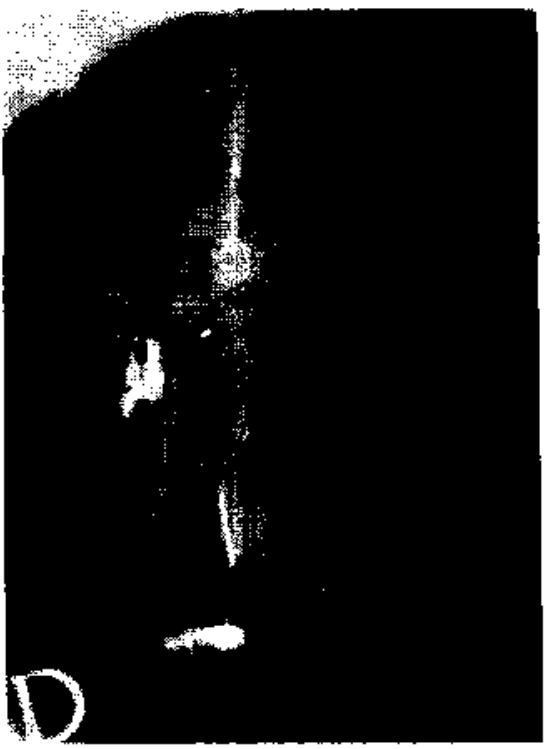

Figura Nọ 3,- Pielografía directa. Uréter izquierdo se inyecta solo en su tercio distal. Deformación pielocelicilar derecha. Rinón muldeistico izquierdo e hipoplesia y pielonefritis derecha. 
La anatomía patológica en todos los casos se caracterizó por los siguientes hechos: a) aspecto macroscópico: quistes múltiples de diferentes timaños que adoptan el aspecto de racimo; ausencia de pelvis $\mathrm{y}$ utéter atrésico o transformado cn

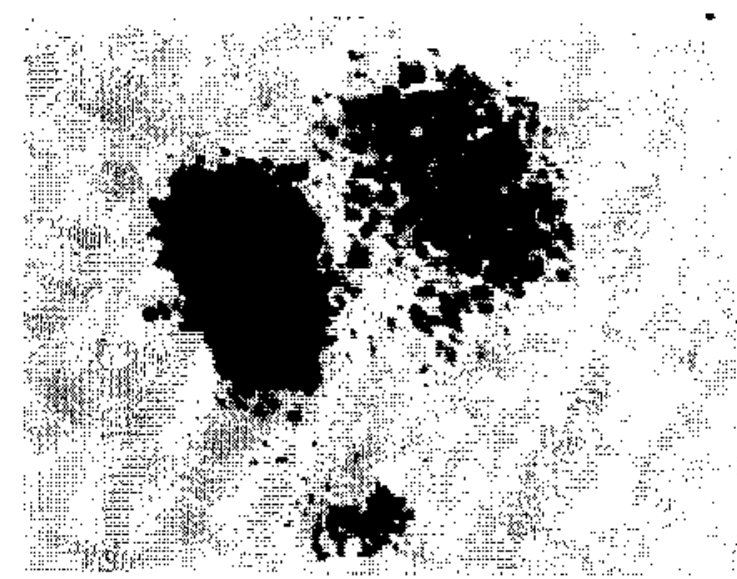

figura NO 4.- Cintigrama Renal, Caso 1.- Riñón multicístico serecho, (dísplásico).

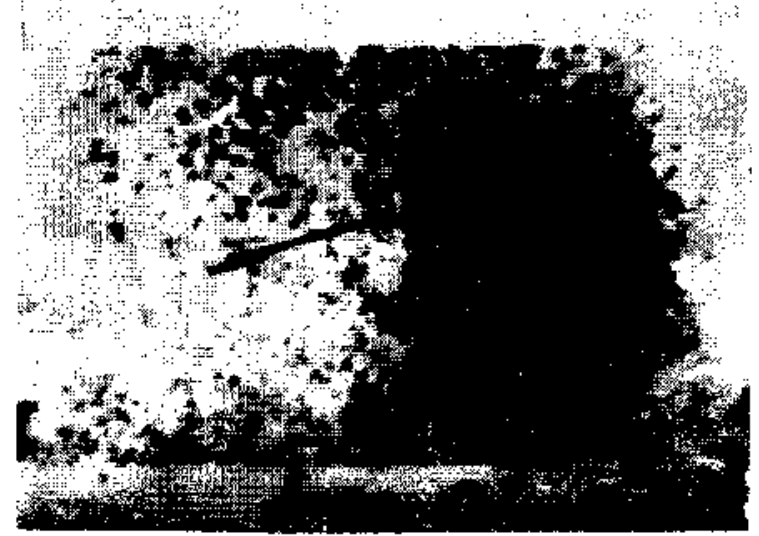

Figutra No 5.- Caso Ni3, Cintigrama renal, Riñón multicístico izquierdo.

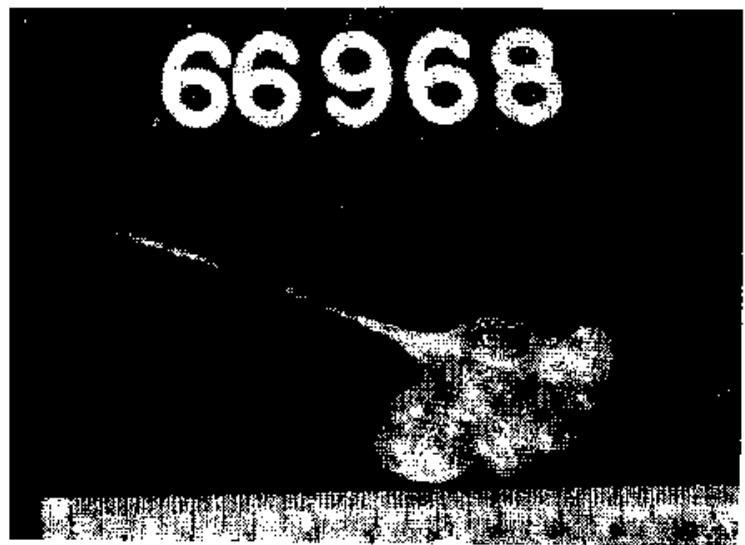

Figura No 6.- Riñon multicístico Quistes mültiples, ausenciน de pelvis, urêter atrésico. cordón fibroso; otras veces dilatado y acluido en st segmento distal (Fig. No 6). Aspecto macroscópico: ausencia absoluta de glomérulos y cuando éstos existían presentaban características de inmadurez, a veces adoptando dis;posición en islotes con túbulos más o menos diferenciados. La otra característica fue la presencia de abundante tejido fibroso y cn el caso dos se agrega la presencia de islotes de tejido cartilaginoso que le da el sello característico a las displasias.

El control alejado de los cuatro recién nacidos a los cuales se le practicó nefrectomía y que no presentaban patología asociada, ha demostrado una excelente evolución desde los cuatro meses a los tres años y medio después de operados, con un desarrollo pondoestatural satisfactorio y con exámenes de orina y presión arterial normal. El caso cinco, que presenta una hipoplasia y pielonefritis crónica del otro riñón, ha evolucionado con una insuficiencia renal compensada y con marcado retraso pondoestatural.

Cómentario. No está dentro de los objetivos de este trabajo entrar a discutir las diversas teorías que tratan de explicar la formación de los quistes renales. Sin embargo, es conveniente precisar algunos conceptos en relación a las anomalías estructurales congénitas ya las formaciones quísticas de los riñones, ya que la nomenclatura aparece muchas veces confusa.

Las lesiones quísticas múltiples del riñon vueden ser hereditarias, congénitas o adquiridas. E1 riñón poliquístico es una enfermedad heređitaria, pero debe recalcarse que no todas las lesiones quísticas múltiples del riñón son riñones poliquísticos, por el contrario, son mucho más frecuentes las lesiones de tipo congénito y entre ellas especialmente el rin̄ón multicistico. Los quistes adquiridos pueden ser secundarios a lesiones inflamatorias, tumorales o cicatrices traumáticas de los riñones.

Por otra parte el concepto de displasia renal implica desartollo anormal de los nefrones que resulta en malforrnación renal total o parcial. Es así como debe diferenciarse entre la enfermedad quística por una parte y la displasia renal segmentaria con parénquima renal alterado sólo en determinadas zonas. Debe quedar en claro que el concepto de displasia no tiene que implicar obligadamente un rin̄ón macroscópicamente alterado, sino que puede manifestarse exclusivamente por lesiones microscópicas focales en riñores aparentemente normales. Así los riñones displásicos pueden tener cualquier forma o tamaño y la displasia puede ser cortical o medular, total o parcial, focal o segmentaria. Lo que le da un sello característico a los tejidos displásicos es la presencia de tejido cartilaginoso metaplásico.

Cono conciusión: en los riñones displásicos puede haber quistes o puede no haberlos y las 
lesiones quísticas cuando las hay pueden ser macro o microscópicas.

Los posibles mecanismos patogénicos de la enfermedad quística renal pueden ser: 1.- Defectos de los cuadros de crecimiento embrionario y 2.- Exposición crónica de nefrones ya formados a factores tóxicos.

Cualquier tipo de agresión durante el período de desarrollo normal de los riñones puede producir alteraciones estructurales en ellos; cspecialmente importantes son las infecciones de tipo viral, los tóxicos o alteraciones metabólicas. Utimamente se ha investigado el efecto de la difenilamina sobre el riñón fetal de la rata: se administró esta sustancia a la rata madre en la última semana de preñez; los riñones de las ratas neonatas mostraron en forma constante dilataciones de los túbulos renales; al efectuar microdisección se apreció que las lesiones quísticas se encuentran en el túbulo proximal. También se ha demostrado experimentalmente que el desarrollo del riñón fetal in vitro requiere de concentraciones relativamente altas de potasio en el medio (8).

Ahora bien, la lesión quística que resulta de la administración mantenida de difenilamina en la rata adulta es diferente. Safouch y cols. demostraron alteración funcional - disminución de la capacidad de concentración antes de que aparezcan lesiones morfológicas. Al efectuar microdisección se encontró que las lesiones quísticas están en los túbulos colectores.

Con todas estas pretnisas, puede comprenderse el por qué aún no se logra una buena clasificación de Ias enfermedades quísticas del riñón. En la tabla No 2, exponemos una clasificación clínica que, creemos, refleja las diferentes enfermedades quísticas de los riñones (12).

Dentro de las displasias renales está el riñón multicístico unilateral congénito, motivo de esta presentación y que como ya dijimos constituye la enfermedad quística más frecuente en la lactancia.

La enfermedad poliquística adopta dos formas: la infantil y la adulta. Actualmente se considerart como un mismo cuadro que se diferencian sólo por el diferente grado de compromiso del parénquima funcionante. En la forma infantil habría mayor número de nefrones comprometidos o comprimidos por los quistes, lo que llevaría a manifestaciones más precoces de insuficiencia renal y muerte a corto plazo. En la forma adulta el compromiso del tejido funcionante sería menor y las manifestaciones clínicas serían más tardías, alrededor de la cuarta o quinta década de la vida, también con signos de insuficiencia renal y dos riñones voluminosos y abollonados.

En el tercer grupo figuran las enfermedades quísticas de la médula renal; se describen aquí dos formas principales: Enfermedad quística medular
TA B L A NO 2

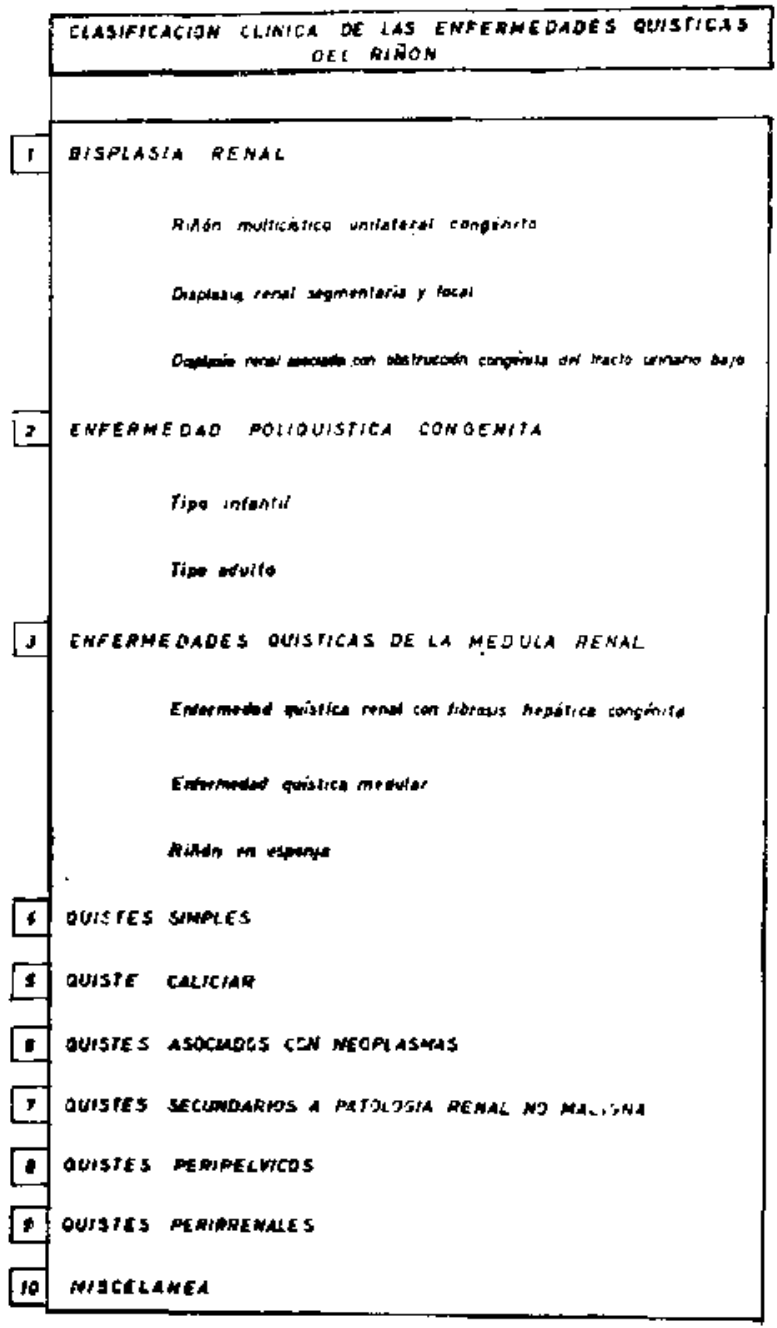

propiamente tal que corresponde a quistes a nivel de las pirámides que no comunican con la pelvis. Una variedad de esta forma de enfermedad quística medular es el llamado Riñón en esponja descrito en 1948 por Cacchi y Ricci. Se caracteriza por la existencia de dos riñones grandes a veces lobulados, en cuyas pirámides hay numerosos quis. tes. Los quistes no afectan ni a las columnas de Bertin ni a la corteza. En el estudio histológico los túbulos colectores presentan dilataciones fusiformes o diverticulares. Estos quistes comunican con Ia pelvis. Aunque son pocos los casos que han sido diagnosticados en la infancia, nosotros observamos esta afección en un recién nacido que falleció con hiponatremia marcada por grandes pérdidas urinarias de sodio y que será motivo de otra publicación

En otros grupos están los quistes simples uni o multiloculares, los quistes caliciares, los quistes asociados a neplasmas ya sea por degeneración maligna de un quiste simple o por degeneración quística de un tumor maligno; los quistes secun- 
darios a patología renal no maligna, los quistes peripélvicos y perirrenales y por último un grupo miscelánico en que podría estar situado el quiste hidatídico.

Tomando en cuenta todas estas consideraciones, $\mathrm{y}$ a pesar que muchos autores lo ponen en duda, podemos decir que el riñón multicístico constituye una entidad bien definida.

Del análisis de nuestros casos podenos sacar algunas conclusiones de importancia. El riñón multicístico se presenta fundamentalmente en el período del recién nacido como una tumoración abdominal palpable, constituyendo este hecho la única manifestación de enfermedad; el examen de orina y la presión arterial son normales y el niño se alimenta y desarrolia en forma satisfactoria.

Tanto la pielografía de eliminación como el cintigrama renal muestran una exclusión renal del mismo lado en que se palpa la masa. Al respecto es preciso señalar algunas bondades de la cintigrafía renal en el estudio de estos casos, especialmente en el periodo del recién nacido y lactante menor. De todos conocidas son las dificultades técnicas y de interpretación que presenta la pielografía de eliminación en el niño pequeño; generalmente no es posible hacer una preparación adecuada y la gran cantidad de gases y contenido intestinal a menudo no permiten visualizar ni delimitar bien las sombras renales. Con la cintigrafía renal se obvian estos inconvenientes y se obtienen imágenes bastante claras en relación a forma, tamaño, posición y diferente grado de contraste de los rin̂ones; esta última apreciación sería además, en cierto modo, un índice grosero del funcionalismo renal. Consideramos por lo tanto, que la cintigrafía renal constituye un método diagnóstico útil, rápido, de bajo costo, de menores dificultades técnicas y de meenor exposición radiactiva que la pielografía. Su empleo es de gran utilidad especialmente en el estudio de las enfermedades quísticas y tumorales del riñón (11).

A pesar de todas las dificultades que anotamos para la interpretación de la pielografía de eliminación en el recién nacido y lactante pequeño, Doberti (5) afirma que es posible observar en algunos casos de riñón multicístico la delimitación de las imágenes quísticas por una delgada lámina en forma de círculo que dibuja los quistes en forma precisa. Estas imágenes no las hemos observado en las pielografías efectuadas en nuestros casos en que la histología no demostró nefrones capaces de función adecuada.

El tratamiento en todos los casos consistió en la nefrectomía. El riñón multicístico constituye un riñón absolutamente no funcionante y es discutible por lo tanto la necesidad de evaluar el riñón del lado opuesto para decidir la nefrectomía. La exploración pielográfica y cintigrafica del riñón opuesto nos puede mostrar, eso sí, la presencia de otra malformación o patología asociada que cambia totalmente el pronóstico como en el caso No 5.

En la literatura nacional Izzo (6) en 1966 presenta 11 casos de riñón multicístico estudiados en el Hospital Calvo Mackenna en el transcurso de ocho años. En todos se practicó nefrectomía falleciendo tres de ellos y en uno se describe un rînón multicístico bilateral lo que es extraordinariamente poco frecuente.

La anatomía patológica nos muestra invariablemente en todos los casos la presencia de abundantes quistes de diferentes tamaños que adoptan la disposición en racimo. Tanto la pelvis renal como el uréter son atrésicos a este último, está transformado en un cordón fibroso o está permeable sólo en su tercio distal.

El estudio histológico muestra ausencia total de glomérulos y en otros casos glomérulos inmaduros de tipo fetal rodeados de túbulos dilatados y abundante tejido fibroso y a veces nidos de tejido cartilaginoso. Es posible también observar en algunos casos la presencia de calcificaciones.

E1 diagnóstico diferencial del riñón multicístico del recién nacido debe hacerse con todos aquellos cuadros que se manifiestan por un tumor de flanco. Cuando además de la masa abdominal palpable exista compromiso del estado general, debe pensarse en tres posibilidades: una trombosis de vena renal, una oclusión arterial o una hemorragia de la cápsula suprarrenal. Las Jesiones vasculares propias del riñón producen hematuria macro o microscópica y la pielografía muestra una exclusión renal en todos los casos. La oclusión arterial es extraordinariamente rara y la mayoría de los casos son trombosis venosas. En la hemorragia suprarrenal además del cuadro clíinico denominado pseudoneumonía del recién nacido, que puede ser no tan categórico, el examen de orina es normal y la radiología puede mostrar calcificaciones precoces o bien desplazamientos de la zona renal por una masa suprarrenal; además el cintigrama mostrará riñones normales.

Cuando la masa abdominal palpable constituye la única manifestación de enfermedad y no hay compromiso del estado general, el diagnóstico diferencial debe hacerse con los siguientes cuadros:

a) Hidronefrosis unilateral congénita, general-mente por estenosis pielouroteral; en etapa temprana cuando aún no hay atrofia parenquimatosa; tanto la pielografía como la cintigrafía no dan exclusión renal, sin embargo cuando el aumento de la presión retrógrada se mantiene por más tiempo $y$ produce la atrofia del parénquima funcionante se llega a la exclusión renal y aquí el diagnóstico 
diferencial suele ser muy difícil como sucedió con un enfermo que se operó al año de edad con el diagnóstico de riñón multicístico y resultó ser una hidronefrosis congénita por estenosis pielonreteral con atrofia total de la corteza renal.

b) Hipertrofia renal compensadora por agenesia renal contralateral. Aquí se palpa un riñón aumentado de tamaño sin compromiso del estado general. La pielografía y el cintigrama muestran una exchusión renal al lado opuesto a aqueI en que se palpa la masa. Igualmente podrá dar una masa renal una duplicación renal y el diagnóstico diferencial también se hará por radiología y cintigrafía.

c) Tumor renal. Aunque el diagnóstico diferencial es difícil, la pielografía y la cintigrafía nos pueden oricntar en el sentido de no mostrar una exclusión renal y en cambio pueden mostrarnos deformidades $o$ ausencia de contraste localizados.

d) Sindrome transitorio de riñón grande con hematuria del recién nacido. Es poco frecuente y su diagnóstico diferencial difícil; se acompaña generalmente de elevaciốn de la uremia por encima de $1 \mathrm{gr}$. $/ \mathrm{tt}$. Se ha relacionado este sindrome trombosis de vena renal de evolución espontánea $y$ favorable.

e) Por último el diagnóstico diferencial son el riñón poliquístico es fácil de hacer, considerando que se trata de una afección bilateral con glomérulos maduros y funcionantes. No hay exclusión ni pielográfica ni cintigráfica; la pelvis se muestra aracniforme y el uréter es normal y se contrasta en toda su extensión.

Dentro de las complicaciones del riñón multicístico se describen la roțura y hemorragia, la infección secundaria y la degeneración maligna; hechos que personalmente no hemos observado. Otro hecho, que ya no es una complicación, pero que hay que tener presente es el observado por Cenđrón, citado por Roger (7), quien afirma que en un tercio de los casos de riñón multicístico existe en el lado opuesto una estenosis ureteral alta con dilatación pielocaliciar.

En cuanto al pronóstico podemos decir que es excelente después de la nefrectomía cuando no existe patología asociada en el otro riñón. Así lo demuestra el control alciado de nuestros casos. Los cuatro niños que se operaron en el período de! recién nacido y que no presentaban patología asociada se han desarrollado normalmente con exámenes de orina. presión arterial y examen clínico normal por períodos que van de los cuatro meses a los tres años cinco meses después de la nefrectomía. En el caso No 5 en que cxiste una hipoplasia renal con pielonefritis crónica del otro riñón la cvolución se caracteriza por insuficiencia renal compensada con marcado retraso pondoestatural y cuyo pronóstico lógicamente no depende del riñón multicístico extirpado.

\section{RESUMEN}

Se presentan 5 casos de riñón multicístico en el niño observados entre 1966 y 1970 en el Departamento de Pediatria del Hospital San Juan de Dios. Cuatro recién nacidos que ingresan por tumor abdominal palpable y un lactante mayor que consulta por desnutrición y signos de insuficiencia renal.

Se revisan las caracteristicas clínicas y los métodos diagnósticos, enfatizando el valor tanto del estudio pielográfico como de la cintigrafía renal.

Se exponen las características anatomopatologicas de las piezas obtenidas por nefrectomia.

Se comenta sobre las anomalias estructurales congénitas y las enfermedades quísticas de los riñones, presentando tuna clasificación al respecto.

Se plantea el diagnóstico diferencial con otros cuadros que se manifiestan como tumor de flanco en el reciên nacido.

Se hace mención de las complicaciones más frecuentes y se insiste en el excelente pronóstico de la afección después de la nefrectomía como lo demuestra el control alejado de los casos presentados.

\section{BibliografíA}

1.-Longino, L. A.; Martin, L.W. Abdominal masses in the newbort. Pediatrics 21: 598, 1958.

2.- Staubitz,W. J.; Jewett, T. C. Renal cystic disease in childhood. J. of Urology 90: 8, 1963.

3.-Pathak, I. G.; Williams, D. 1. Multicystic and cystic displastic kidneys. Brit. J. of Urology 36: 319 , 1964.

4.-Mari, M. Malformaciones congénitas. Edit. Alambra.. Madrid, 1957.

5.-Deberti, Izzo, Soerensen. Tumores renales y perirTenales del recién nacido. VII Congreso Interamecano de Radiología, Venezuela, 1964.

6.- Izzo, C'. Riñón multicístico del recién nacido. Ar. Sec. Cir, de Chile; XVIII. No 3, 1966.

7.-Roger, P.; Mathieu, H.; Habih, R. Problemas Actuales de Nefrolagía Infantil. Ediciones Toray, $\mathbf{S}$. A.. Barcejona, 1965.

8.-Crocker, J. F.; Brown, D. M.; Vernier, R. L Defectos congénitos de los riñones. Clin. Ped. $N$. Amer,: 355, Mayo, 1971.

9.-Berastein, J.: 'Trastornos quísticos hereditarios de los riñones. Clin. Ped. N. Amer.: 435, Mayo, 1971.

10.-Bernstein, $I$ : Morfogénesis del desarrollo anormal del parénquimá renal. Clin. Ped. N. Amer.: 395, Mayo, 1971.

11.-Mayne, D.; Norero, C.; Maira, J.; Velnsco, C.; Goudie, $A$. Valor de la cintigrafia renal en pediaIría. Rev. Med, Chile, 100: 187, 1972.

12.-- Spence, H. M.; Singlion, R.: What is sponge kidney disease and where does is fit in the spectrum of cystic disorders? J. Urol,, 107, 176, 1972. 